\title{
REVIEW
}

\section{Managing chronic myeloid leukemia patients intolerant to tyrosine kinase inhibitor therapy}

\author{
DJ DeAngelo
}

The outcomes for patients with chronic myeloid leukemia have improved dramatically with the development and availability of BCR-ABL1 tyrosine kinase inhibitors (TKIs) over the past decade. TKI therapy has a superior safety profile compared with the previous standard of care, interferon- $\alpha$, and most adverse events (AEs) observed with front-line and second-line TKI treatment are managed with supportive care. However, some patients are intolerant to TKI therapy and experience AEs that cannot be managed through dose reduction or symptomatic treatment. Careful management of AEs helps patients to remain adherent with treatment and increases their chances for successful outcomes. Proactive vigilance for potential AEs and treatment strategies that reduce symptom burden will help to minimize patient intolerance. This review discusses the most common AEs associated with intolerance to TKI therapy and treatment strategies to help manage patients at risk for or experiencing these events.

Blood Cancer Journal (2012) 2, e95; doi:10.1038/bcj.2012.30; published online 19 October 2012

Keywords: chronic myeloid leukemia; dasatinib; imatinib; intolerance; nilotinib; tyrosine kinase inhibitors

\section{INTRODUCTION}

The tyrosine kinase inhibitor (TKI) imatinib mesylate (Gleevec, Novartis Pharmaceuticals Corporation, East Hanover, NJ, USA) has transformed the treatment of patients with chronic myeloid leukemia (CML). Based on positive findings from the International Randomized Study of Interferon Versus STI571 (IRIS) trial, ${ }^{1}$ published in 2003, imatinib quickly replaced interferon- $\alpha$ as the standard of care. Imatinib has prolonged survival in newly diagnosed patients with chronic-phase (CP) CML; patients from the IRIS study have been followed now for 8 years. ${ }^{2}$ Their survival rate is $85 \%$ overall and $93 \%$ when only patients with CML-related deaths and those who have not received stem cell transplant are considered. The more potent BCR-ABL1 TKIs, dasatinib (Sprycel, Bristol-Myers Squibb Company, Princeton, NJ, USA) and nilotinib (Tasigna, Novartis Pharmaceuticals Corporation), were approved by the US Food and Drug Administration (FDA) in 2006 and 2007, respectively, as second-line agents in patients with imatinib resistance or intolerance, and in 2010 both agents received FDA approval for treatment of patients with newly diagnosed CML., ${ }^{3,4}$

FDA approval for use of nilotinib in newly diagnosed patients with CML-CP was based on data from the Evaluating Nilotinib Efficacy and Safety in Clinical Trials-Newly Diagnosed Patients (ENESTnd) Study comparing nilotinib with imatinib. ${ }^{5}$ Positive results comparing dasatinib with imatinib in newly diagnosed patients from the Dasatinib versus Imatinib in Patients With Newly Diagnosed Chronic Phase CML (DASISION) Study also have been reported. ${ }^{6}$ Imatinib, dasatinib and nilotinib together represent a formidable treatment approach for patients with CML. As with all medication, the effectiveness of TKls relies on their proper use, including good adherence, which in turn depends partly on drug tolerability.

The importance of management of adverse events (AEs) in CML is underscored by the association between the occurrence of AEs and reduced treatment adherence. ${ }^{7,8}$ High symptom burden, which can be exacerbated by treatment-related AEs, often leads to interruption of treatment or decreased dose or frequency of treatment. $^{7-9}$ Consequently, lower levels of adherence are associated with suboptimal responses to imatinib, 7,10,11 and several groups have shown the negative impact of reduced adherence on long-term achievement or maintenance of responses, and event-free survival. ${ }^{7,12,13}$ Patients with lower rates of adherence had significantly reduced likelihood of achieving major molecular response or complete molecular response at 6 years, ${ }^{7}$ higher probability of losing complete cytogenetic response at 2 years, and lower rates of event-free survival at 5 years, compared with more adherent patients. A proactive strategy to alleviate AEs before they become serious or affect adherence is therefore necessary.

For physicians who are incorporating TKIs into their treatment armamentarium, familiarity with the $A E$ profiles associated with TKI therapy allows early identification and management of AEs or intolerance. Some of the AEs have been reported with all of these agents, including cardiac AEs, rash, nausea, fatigue, headache, myelosuppression and elevated liver enzymes. Other AEs are more prevalent with one TKI than another. In addition, the frequency and intensity of AEs differ when TKIs are used in first-line or second-line settings. ${ }^{1,5,6,14}$ This review discusses the most common AEs associated with TKI therapy and outlines treatment strategies to help manage patients at risk for or experiencing these events.

\section{INTOLERANCE TO TKI THERAPY}

In general, intolerance to therapy is acknowledged when a patient develops an AE that cannot be managed through dose reduction or treatment of symptoms. Management strategies for such an event might include interruption or discontinuation of therapy, both undesired actions because of unfavorable outcomes 
associated with them.,10 Intolerance to TKI therapy has been defined through clinical study in CML patients, with variations of the definition provided in different clinical trials.

Safety results from the IRIS trial have provided information concerning frequently observed $\mathrm{AEs}$; the majority of patients treated with imatinib reported AEs, usually grades 1 and 2., ${ }^{15}$ At 5 years of follow-up, the most commonly reported AEs experienced since initiation of treatment were edema (60\%), nausea $(50 \%)$, muscle cramps (49\%), musculoskeletal pain (47\%), diarrhea (45\%), rash or other skin problems (40\%), fatigue (39\%), abdominal pain $(37 \%)$, headache $(37 \%)$ and joint pain $(31 \%)$; the frequencies of these AEs were slightly higher than those reported at the 19-month follow-up. ${ }^{15}$ Grades 3 or 4 AEs included neutropenia $(17 \%)$, thrombocytopenia (9\%), anemia (4\%), elevated liver enzymes (5\%) and other drug-related AEs (17\%; not otherwise described). ${ }^{15}$ Although worsening or newly appearing grades 3 and 4 AEs were minimal after 2 and 4 years of treatment with imatinib, ${ }^{15} 4 \%$ of patients discontinued therapy because of an $A E$ by the 5 -year follow-up. ${ }^{15}$ The AE profile has remained stable and no new events were reported with 8 years of follow-up. ${ }^{2}$ These findings helped to describe imatinib intolerance as the recurrence of grade $\geqslant 3$ nonhematologic toxicity despite appropriate dose reductions and optimal symptom management.

The prescribing information for imatinib notes that severe congestive heart failure and left ventricular dysfunction have occasionally occurred, mainly in patients with other comorbidities and risk factors, including advanced age and previous medical history of cardiac disease. Congestive heart failure and left ventricular dysfunction were seen in $0.7 \%$ of patients in the imatinib arm of the IRIS study. ${ }^{16}$ Kerkelä et al. ${ }^{17}$ investigated the potential cardiotoxicity of imatinib after 10 patients developed severe congestive heart failure while receiving the drug. Myocardial biopsy of two patients with no previous history of coronary artery disease demonstrated membrane abnormalities suggestive of imatinib-induced cardiomyopathy. Furthermore, imatinib had harmful effects on cultured cardiomyocytes and on heart tissue in a mouse model. This effect appeared to be related

Table 1. Percentage of common nonhematologic AEs (all grades and grade $3 / 4$ ) with nilotinib in patients intolerant/resistant to imatinib ${ }^{21,22}$

\begin{tabular}{|c|c|c|c|c|}
\hline & \multicolumn{2}{|c|}{$\begin{array}{l}\text { Chronic-phase } \\
C^{\text {a }}(\mathrm{n}=280)\end{array}$} & \multicolumn{2}{|c|}{$\begin{array}{l}\text { Accelerated-phase } \\
C^{C} L^{\mathrm{b}}(\mathrm{n}=119)\end{array}$} \\
\hline & $\begin{array}{c}\text { All } \\
\text { grades }\end{array}$ & $\begin{array}{c}\text { Grade } \\
3 / 4\end{array}$ & $\begin{array}{c}\text { All } \\
\text { grades }\end{array}$ & $\begin{array}{c}\text { Grade } \\
3 / 4\end{array}$ \\
\hline Abdominal pain & NR & NR & 7 & 1 \\
\hline Alopecia & NR & NR & 8 & 0 \\
\hline Anorexia & NR & NR & 6 & 0 \\
\hline Arthralgia & NR & NR & 5 & 0 \\
\hline Constipation & 12 & 0 & 11 & 0 \\
\hline Diarrhea & 11 & 2 & 9 & 1 \\
\hline Extremity pain & 5 & $<1$ & 5 & 0 \\
\hline Fatigue & 19 & 2 & 10 & 1 \\
\hline Headache & 19 & 2 & 10 & 1 \\
\hline Muscle spasms & NR & NR & 9 & 0 \\
\hline Myalgia & 8 & 1 & 9 & 1 \\
\hline Nausea & 24 & 1 & 10 & 1 \\
\hline Peripheral edema & NR & NR & 5 & 0 \\
\hline Pruritus & 24 & 1 & 20 & 0 \\
\hline Pyrexia & NR & NR & 8 & 1 \\
\hline Rash & 28 & 3 & 22 & 0 \\
\hline $\begin{array}{l}\text { Upper abdominal } \\
\text { pain }\end{array}$ & NR & NR & 5 & 0 \\
\hline Vomiting & 11 & $<1$ & NR & NR \\
\hline
\end{tabular}

to $c-A B L$ inhibition, suggesting that cardiac adverse reactions may be common to all TKIs. ${ }^{17,18}$

\section{SAFETY OF TKIS IN THE SECOND-LINE SETTING}

Nilotinib and dasatinib are effective in treating patients intolerant or resistant to imatinib in $\mathrm{CML}-\mathrm{CP}$, as well as in accelerated-phase (AP) and blast crisis (BC). ${ }^{14,19-23}$ The safety profiles of nilotinib and dasatinib are generally favorable, although the number and intensity of AEs tend to increase in the second-line setting or in advanced phases of CML. This tendency is most readily evidenced by the increased percentage of grade $3 / 4$ cytopenias in second-line versus first-line settings. ${ }^{1,5,6,14}$

\section{Nilotinib}

Nilotinib $400 \mathrm{mg}$ twice daily has been examined in two openlabel phase 2 studies in patients with CML-CP ${ }^{21}$ or CML-AP ${ }^{22}$ and imatinib intolerance or resistance. The most frequent nonhematologic AEs in these studies are shown in Table 1. In the CML$\mathrm{CP}$ study, the most common grade $3 / 4$ hematologic abnormalities were neutropenia (29\%) and thrombocytopenia (29\%). ${ }^{21}$ In the CML-AP study, the corresponding rates of grade 3/4 neutropenia and thrombocytopenia were $21 \%$ and $35 \%$, respectively. ${ }^{22}$ Grade 3/4 elevations in aspartate aminotransferase (1\%), alanine aminotransferase (2-4\%), bilirubin (9\%) and lipase (14-18\%) occurred infrequently in both studies and were not clinically significant for most patients. Despite elevated lipase, pancreatitis was a rare event, reported in three patients $(1 \%)$ in the CML-CP study; ${ }_{i}^{21}$ one patient in the CML-AP study discontinued because of pancreatitis. $^{22}$

With respect to cardiac $\mathrm{AEs}$, prolongation of QT interval corrected by Fridericia's formula $(\mathrm{QTCF})^{24}>500 \mathrm{~ms}$ was observed in four (1.2\%) patients with CML-CP 25 in a phase 2 study and in no patients with CML-AP. ${ }^{21,22}$ Data at 24 months indicated that the safety profile in the longer term was unchanged, and nilotinib retained its favorable risk/benefit ratio. ${ }^{25}$ Cases of peripheral arterial occlusive disease occurring during nilotinib treatment have been identified, mostly in the second-line setting. To date, a total of 24 cases of peripheral arterial occlusive disease have been reported. ${ }^{26-30}$ Most of the patients who developed peripheral arterial occlusive disease on nilotinib had at least one cardiovascular risk factor at baseline, including history of smoking or nicotine use, arterial hypertension, diabetes or dyslipidemia, ${ }^{26,29,30}$ suggesting that nilotinib treatment may aggravate a preexisting condition.

For patients who experience intolerance to first-line imatinib, cross-intolerance to a second-line $\mathrm{TK}$, or the recurrence of an $\mathrm{AE}$ on nilotinib that previously led to imatinib intolerance, is minimal. Of the patients enrolled in the two phase 2 nilotinib studies described above, 95 of $321 \mathrm{CML}-\mathrm{CP}$ patients and 27 of $137 \mathrm{CML}-\mathrm{AP}$ patients were intolerant to imatinib. ${ }^{31}$ Imatinib-intolerant patients were defined as having had persistent grade $3 / 4$ nonhematologic AEs despite supportive care; persistent grade 2 nonhematologic $A E s$, that is, persisting $\geqslant 1$ month or recurring $\geqslant 4$ times despite imatinib dose reduction and supportive care; or grade 4 hematologic toxicity persisting $>7$ days. Cross-intolerance with nilotinib treatment occurred in 4 of 75 CML-CP and -AP patients who were intolerant to imatinib because of nonhematologic $A E s$, and in 23 of 40 patients who were intolerant to imatinib because of hematologic AEs. ${ }^{31}$ Importantly, discontinuation of nilotinib because of an AE was infrequent, occurring in only 7 of $40(18 \%)$ patients, all of whom had recurrent thrombocytopenia.

To further evaluate the safety of nilotinib in a clinical practice setting, Expanding Nilotinib Access in Clinical Trials (ENACT), an ongoing phase $3 \mathrm{~b}$, open-label, multicenter study in imatinibresistant or -intolerant patients, was initiated as a global expanded-access program. ENACT includes patients with CML in 
$\mathrm{CP}, \mathrm{AP}$ or $\mathrm{BC}$. Recently reported results suggest the safety profile is similar to that observed in the phase 2 studies described above. $^{32,33}$

Dasatinib

Four of the SRC-ABL Tyrosine Kinase Inhibition Activity Research Trials (START) phase 2 studies were single-arm trials in patients treated with second-line dasatinib $70 \mathrm{mg}$ once daily; one study (START-R) was a randomized comparative trial of dasatinib $70 \mathrm{mg}$ once daily or high-dose imatinib $400 \mathrm{mg}$ once daily in patients previously resistant or intolerant to imatinib 400 to $600 \mathrm{mg}$ once daily. ${ }^{14,19,20,34,35} \mathrm{AE}$ rates at 8 months in the four single-arm studies are provided in Table 2. Dasatinib was generally well tolerated in all four studies; overall, toxicities were manageable through dose reduction or interruption and resumption at a lower dose. ${ }^{19,20,35}$

The occurrence of pleural effusion and pulmonary arterial hypertension (PAH) is unique to treatment with dasatinib. One group evaluated the occurrence of pleural effusion in patients treated with dasatinib after imatinib failure and found this $\mathrm{AE}$ had developed in $35 \%$ of patients. ${ }^{36}$ The occurrence of pleural effusion in patients receiving TKI therapy for CML is associated with significantly higher health-care resource utilization and represents a substantial financial burden for patients experiencing this $\mathrm{AE}^{37}$ Furthermore, $>60$ cases of $\mathrm{PAH}$ have been identified ${ }^{38-43}$ and 18 cases suspected ${ }^{36}$ in patients treated with dasatinib after prior imatinib therapy. In nearly all cases of $\mathrm{PAH}$, patients were diagnosed with pleural effusion before the development of $\mathrm{PAH}$, suggesting a common mechanism behind these disorders.

Cross-intolerance to dasatinib was evaluated in imatinibintolerant patients in the START study in patients with CML-CP
(START-C). ${ }^{44}$ Imatinib-intolerant patients were defined as those experiencing grade $\geqslant 3$ nonhematologic toxicity or grade 4 hematologic toxicity persisting for $>7$ days and related to imatinib at any dose. In START-C, 3\% of imatinib-intolerant patients developed similar toxicity with dasatinib. ${ }^{44} \mathrm{~A}$ retrospective pooled analysis of two multicenter studies investigated cross-intolerance in imatinib-intolerant patients $(N=271)$, where intolerance was defined the same as in START-C. The analysis demonstrated that although $4 \%$ of imatinibintolerant patients developed similar nonhematologic toxicity with dasatinib, only $1 \%$ discontinued treatment; dose reduction was sufficient for management of most AEs. ${ }^{45}$

\section{SAFETY OF NILOTINIB AND DASATINIB IN THE FRONT-LINE SETTING}

The ENESTnd and DASISION studies demonstrated that nilotinib and dasatinib are more effective than imatinib for attaining complete cytogenetic responses and major molecular responses in newly diagnosed patients with CML-CP. ${ }^{5,6,46-48}$ Safety data from these studies, including the incidence of AEs leading to discontinuation, improve our understanding of front-line TKI safety and tolerability. The overall safety profiles of nilotinib and dasatinib as front-line agents were favorable. Indeed, nilotinib and dasatinib each appeared to be well tolerated compared with imatinib, albeit in different ways based on their distinct AE profiles. Notably, certain AEs, such as hematologic AEs, were less frequent or less severe in the front-line versus the second-line setting.

\section{Nilotinib}

ENESTnd is an ongoing phase 3, randomized, open-label, multicenter study comparing nilotinib $300 \mathrm{mg}$ twice daily $(n=282)$ or

Table 2. Percentage of common nonhematologic AEs (all grades and grade 3/4) and hematologic abnormalities (grade $3 / 4$ ) at 8 months with dasatinib in patients intolerant/resistant to imatinib ${ }^{19,20,35}$

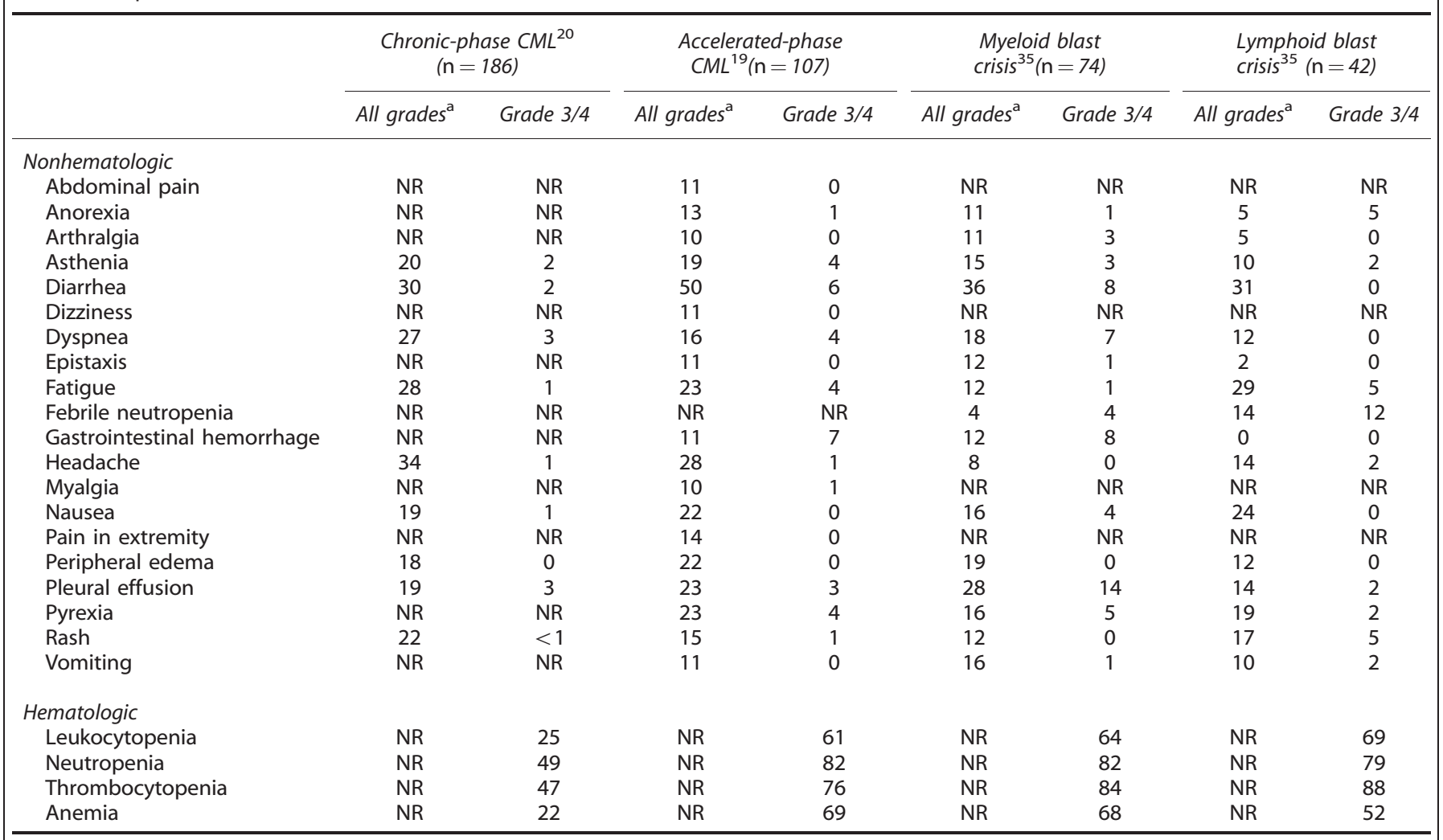

Abbreviations: $\mathrm{AE}$, adverse event; $\mathrm{CML}$, chronic myeloid leukemia; NR, not reported. ${ }^{\mathrm{a}} \mathrm{All}$-grade $\mathrm{AEs}$ reported when frequency was $>10 \%$ for any $\mathrm{AE}$. 
$400 \mathrm{mg}$ twice daily $(n=281)$ with imatinib $400 \mathrm{mg}$ once daily $(n=283){ }^{5,46}$ AE-related discontinuations at 12 months and 24 months were seen in $7 \%$ and $9 \%$ of patients receiving nilotinib $300 \mathrm{mg}$ twice daily, $11 \%$ and $13 \%$ receiving nilotinib $400 \mathrm{mg}$ twice daily and $9 \%$ and $11 \%$ receiving imatinib, respectively. ${ }^{46}$

The most common all-grade and grade 3/4 AEs and hematologic abnormalities are shown in Table 3. Most of the common AEs were mild or moderate in severity. The rates of nausea, diarrhea, vomiting, muscle spasm and edema were higher with imatinib than with either dose of nilotinib. Conversely, rates of rash, headache, pruritus and alopecia were higher with nilotinib at either dose than with imatinib. ${ }^{5}$ The rates of all-grade neutropenia, thrombocytopenia and anemia were higher with imatinib than with either dose of nilotinib. All grade 3/4 cytopenias occurred within the first 2 months. Notably, there were fewer events of grade 3/4 neutropenia in the nilotinib-treated patients than in the imatinib-treated patients; the rates of grade $3 / 4$ thrombocytopenia and anemia were similar in both nilotiniband imatinib-treated patients. ${ }^{5}$ Recent publication of 24-month data and presentation of 3-year follow-up data indicated no change in the AE profile. ${ }^{46,49}$

Biochemical abnormalities were comprehensively reported, and most were mild to moderate in severity. ${ }^{5}$ Increased levels of total bilirubin, glucose, lipase, alanine aminotransferase and aspartate aminotransferase occurred more often in the nilotinib arm than in the imatinib arm of the study; decreased phosphate and increased creatinine were reported less frequently in nilotinib- versus imatinib-treated patients. ${ }^{5}$

QTc prolongation has been a concern with nilotinib and dasatinib. ${ }^{3,4}$ Although patients were closely monitored for QT prolongation and changes in left ventricular ejection fraction, no patient in any group had a QTcF interval $>500 \mathrm{~ms}$, or a decrease from baseline in the mean left ventricular ejection fraction. In all three treatment groups combined, a total of 11 patients reported an $\mathrm{AE}$ related to ischemic heart disease in the ENESTnd study; one event led to treatment discontinuation. ${ }^{5}$ Physicians who prescribe nilotinib in the front-line setting should be aware that, compared with imatinib, the incidences of rash, pruritus (scalp) and headache are higher, and the incidences of gastrointestinal (Gl) AEs, myalgia and arthralgia are lower. ${ }^{5}$ Nilotinib also requires periodic electrocardiogram monitoring for QTC prolongation and laboratory monitoring for potential biochemical abnormalities. Additional testing by electrocardiogram is recommended at baseline, 7 days after initiation of nilotinib therapy and following any dose adjustments.

\section{Dasatinib}

DASISION is an ongoing phase 3, open-label, multinational, randomized study comparing dasatinib $100 \mathrm{mg}$ once daily $(n=259)$ with imatinib $400 \mathrm{mg}$ once daily $(n=260){ }^{6,48}$ The $12-$ month AE-related discontinuation rates were $5 \%$ with dasatinib $100 \mathrm{mg}$ and $4 \%$ with imatinib $400 \mathrm{mg}$. Discontinuation rates remained low after a minimum of 24 months of follow-up: $7 \%$ for dasatinib-treated patients and 5\% for imatinib-treated patients. ${ }^{48}$

The most common all-grade and grade 3/4 AEs and hematologic abnormalities in the DASISION study are shown in Table 3. With the exception of headache, most of the common AEs (nausea, vomiting, muscle inflammation, rash, fluid retention (described as superficial edema, pleural effusion and 'other') and headache) were more frequent with imatinib than with dasatinib. Among the types of fluid retention, pleural effusions (grades 1 and 2) were seen only with dasatinib; three patients discontinued treatment related to grade 2 pleural effusion. ${ }^{6} \mathrm{Gl}$ or other bleeding

Table 3. Percentage of common nonhematologic AEs and hematologic abnormalities (all grades and grade 3/4) reported in the ENESTnd and DASISION studies at 12 months $s^{5,6}$

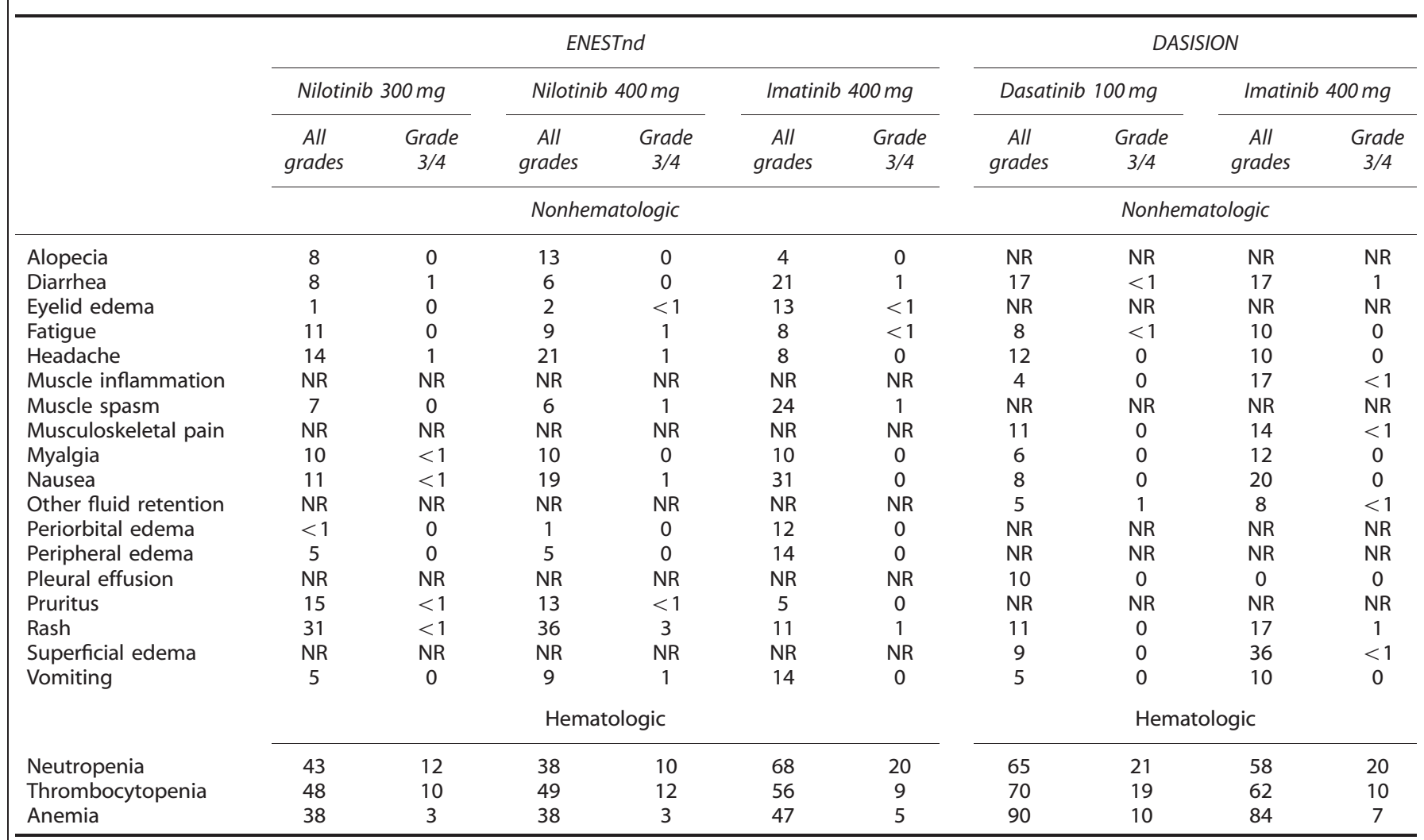

Abbreviations: $\mathrm{AE}$, adverse event; $\mathrm{CML}$, chronic myeloid leukemia; NR, not reported. 
events occurred in $5 \%$ of dasatinib- and $5 \%$ of imatinib-treated patients; these were grade $3 / 4$ events in one patient receiving dasatinib and two patients receiving imatinib. ${ }^{6}$ Rates of all-grade hematologic abnormalities were higher with dasatinib than with imatinib, and nearly three-fourths of the hematologic AEs occurred within the first 4 months of initiation of the study. Comparable rates of grade $3 / 4$ neutropenia and anemia were seen with imatinib; the rate of grade 3/4 thrombocytopenia was higher with dasatinib.

Grade 3/4 hypophosphatemia occurred in 4\% of patients receiving dasatinib and $21 \%$ receiving imatinib. Among the discontinuations in the imatinib group, one patient discontinued therapy because of hypophosphatemia and one because of hypocalcemia. One patient in the dasatinib group discontinued treatment because of an elevated serum creatine phosphokinase level. ${ }^{6}$

QTc prolongation was also monitored in the study; $2 \%$ of patients receiving dasatinib and $4 \%$ receiving imatinib had a QTC interval between 450 and $500 \mathrm{~ms}$; one patient in each treatment group had a QTC interval $>500 \mathrm{~ms}^{6}$ A similar AE profile was observed with minimum follow-up of 24 months of dasatinib treatment. ${ }^{48}$

Results from a phase 2 study (SO325) carried out by four North American cooperative groups that compared dasatinib $100 \mathrm{mg}$ with imatinib $400 \mathrm{mg}$ were recently reported. ${ }^{47}$ The discontinuation rate because of toxicity was slightly higher than that observed in the DASISION study for both dasatinib- and imatinib-treated patients, $15 \%$ and $11 \%$, respectively, but the overall $A E$ profile was similar to that reported in the DASISION study.

In prescribing dasatinib in newly diagnosed CML patients, physicians should be aware of the greater incidence of pleural effusion compared with imatinib, as well as new information regarding cardiac adverse reactions in the recently revised prescribing information for dasatinib. $3,6,47$ Compared with imatinib, dasatinib has lower rates of myalgia and GI AEs.

\section{Agents in development for CML treatment}

Several new agents are in development for the treatment of CML, which will provide physicians treating patients who are intolerant to a particular agent more options to consider when a switch in therapy is required. These include the TKIs bosutinib/SKI-60, ${ }^{50,51}$ ponatinib/AP24534, ${ }^{52,53}$ DCC-2036 $6^{54,55}$ and INNO-406; ${ }^{56}$ the Aurora kinase inhibitor danusertib/PHA-739358; ${ }^{.7}$ and the plant alkaloid omacetaxine/homoharringtonine. ${ }^{58}$ AEs observed in phase 1, 2 and 3 studies with many of these agents in development have been published or reported in abstract form and are summarized in Table 4.

Bosutinib has been tested as a second-line treatment in CML patients in $\mathrm{CP}^{50}$ and $\mathrm{AP} / \mathrm{BC}^{59}$ and for front-line treatment of patients with newly diagnosed CML-CP. ${ }^{60}$ The most common AEs in all studies were Gl: a phase $1 / 2$ study of patients with CML-AP/ $\mathrm{BC}$ or acute lymphoblastic leukemia with imatinib resistance or intolerance reported diarrhea in $74 \%$, vomiting in $43 \%$ and nausea in $48 \%$ of patients. ${ }^{61}$ In the phase 3 front-line treatment study, Gl events of diarrhea (69\%), vomiting (32\%) and abdominal pain (13\%) were also notable. ${ }^{6,62}$ In all studies, GI AEs were typically grades $1-2$, manageable and transient, diminishing in frequency and severity after the first 3 to 4 weeks of treatment. ${ }^{50,60,62}$

Bosutinib was also associated with elevated liver function tests. Grade 3/4 alanine aminotransferase/aspartate aminotransferase elevations were observed in 10 to $15 \%$ of patients with CML-CP and $7 \%$ of patients with CML-AP/BC or acute lymphoblastic leukemia. ${ }^{50,51,61}$ Rates of grade $3 / 4$ hematologic laboratory abnormalities in CML-CP were: thrombocytopenia, 24\%; neutropenia, 18\%; and anemia, $13 \%$ when bosutinib was administered as second-line treatment, ${ }^{50}$ and thrombocytopenia, 14\%; neutropenia, 11\%; and anemia, $8 \%$ when given as first-line treatment. $^{60}$ Corresponding rates of grade $3 / 4$ hematologic abnormalities of any causality in patients with CML-AP/BC or acute lymphoblastic leukemia were higher than in patients with CML-CP and included thrombocytopenia, 60\%; neutropenia, 39\%; and anemia, $34 \%{ }^{61}$

Results from a phase 1 dose-finding study of ponatinib in patients with refractory hematologic malignancies were recently presented. ${ }^{63}$ Dose-limiting toxicities were identified as an elevation of pancreatic enzymes and pancreatitis in 4 of 14 patients treated at a $60 \mathrm{mg}$ dose, and grade 3 rash in 1 of 22 patients treated at a $45 \mathrm{mg}$ dose. All dose-limiting toxicities were reversible. A preliminary report of a phase 2 study of second-line ponatinib in 397 patients with $\mathrm{CML}$ or $\mathrm{Ph}+$ acute lymphoblastic leukemia showed that pancreatitis $(n=15,3.8 \%)$ was the most frequent serious $A E$. Other serious $A E s$ included diarrhea, anemia, febrile neutropenia and pyrexia. ${ }^{64}$

\section{MANAGEMENT OF ADVERSE EVENTS}

With the occurrence of an $A E$, the physician is faced with three options: discontinuation of therapy, management of the $A E$ or switching therapy to an alternative TKI. As mentioned previously, discontinuation of therapy is the least favorable option because of poor outcomes associated with therapy interruption or termination. Switching therapy to another TKI may be an appropriate strategy for some patients and bears consideration. Minimal crossintolerance observed with dasatinib and nilotinib offers imatinibintolerant patients viable therapeutic options. Although imatinib intolerance in clinical studies has been defined rigorously, clinicians should be aware that persistent grades 1 and 2 toxicities are important when considering a patient's tolerance to therapy. Patient self-discontinuation of treatment or decreased adherence to medication may occur because of less severe but continual AEs. For many patients, management of AEs is sufficient for continuation of their current therapy. Updated guidelines from the National Comprehensive Cancer Network (NCCN) provide recommendations for the management of toxicity associated with imatinib, nilotinib and dasatinib ${ }^{65}$ and are summarized in this review.

\section{Common nonhematologic AEs}

Gl symptoms (nausea, vomiting and diarrhea) are frequently associated with TKIs, but they are usually mild or moderate. Nausea associated with imatinib or dasatinib can be mitigated by taking the medications with a meal and a large glass of water. Symptomatic treatment is recommended for nausea associated with nilotinib because it is taken under fasting conditions, ${ }^{65}$ and for other GI AEs associated with TKIs, such as diarrhea. Patients should be informed that grapefruit and grapefruit juice must be avoided with TKI therapy, because these substances inhibit hepatic cytochrome p450 enzymes that metabolize TKIs, thereby increasing drug levels unpredictably. ${ }^{66}$

Fluid retention is a common $A E$, especially with imatinib and dasatinib. With imatinib, fluid retention often involves the eyelid, periorbital region or lower legs. ${ }^{66}$ Patients with peripheral edema or generalized fluid retention should be weighed and monitored closely. ${ }^{65,66}$ With imatinib, edema and fluid retention are often mild; management includes diuretics and salt restriction. If these AEs are severe, dose reduction, interruption or discontinuation is recommended. ${ }^{65}$

Pleural effusions can be serious, and early identification is critical to their successful management. Patients should be advised that chest pain, dyspnea and dry cough must be reported promptly. ${ }^{67}$ If pleural effusion is confirmed by X-ray, treatment interruption is suggested until the effusion resolves; a short course of steroids also can be considered. ${ }^{3}$ Therapy with dasatinib should 
Table 4. Summary of adverse events reported for anti-CML agents in development

\begin{tabular}{|c|c|}
\hline \multicolumn{2}{|c|}{ Bosutinib } \\
\hline Chronic-phase $C M L^{71-75}$ & Accelerated-phase/blast crisis $C M L^{59,76}$ \\
\hline $\begin{array}{l}\text { Grade } 1 / 2 \text { nonhematologic toxicity } \\
\text { Diarrhea } \\
\text { Nausea } \\
\text { Vomiting } \\
\text { Abdominal pain } \\
\text { Rash } \\
\text { Asthenia } \\
\text { Increased ALT/AST }\end{array}$ & $\begin{array}{l}\text { Grade } 1 / 2 \text { nonhematologic toxicity } \\
\text { Diarrhea } \\
\text { Nausea } \\
\text { Vomiting } \\
\text { Pleural effusion } \\
\text { Fluid retention }\end{array}$ \\
\hline $\begin{array}{l}\text { Grade } 3 / 4 \text { nonhematologic toxicity } \\
\text { Diarrhea } \\
\text { Rash } \\
\text { Increased ALT } \\
\text { Pleural effusion } \\
\text { Pericardial effusion }\end{array}$ & $\begin{array}{l}\text { Grade } 3 / 4 \text { nonhematologic toxicity } \\
\text { Diarrhea } \\
\text { Vomiting } \\
\text { Pneumonia } \\
\text { Increased ALT } \\
\text { Pleural effusion } \\
\text { Fluid retention }\end{array}$ \\
\hline $\begin{array}{l}\text { Grade } 3 / 4 \text { hematologic toxicity } \\
\text { Thrombocytopenia } \\
\text { Neutropenia } \\
\text { Anemia }\end{array}$ & $\begin{array}{l}\text { Grade } 3 / 4 \text { hematologic toxicity } \\
\text { Thrombocytopenia } \\
\text { Neutropenia } \\
\text { Anemia }\end{array}$ \\
\hline $\begin{array}{l}D C C-2036^{\text {(ref.55) }} \\
\text { Peripheral neuropathy } \\
\text { Lower extremity weakness }^{\mathrm{a}} \\
\text { Slurred speech } \\
\text { Eruptive nevi } \\
\text { Dry mouth } \\
\text { Constipation } \\
\text { Diarrhea } \\
\text { Paresthesia } \\
\text { Retinal vein occlusion } \\
\text { Pancreatitis }\end{array}$ & \\
\hline $\begin{array}{l}\text { INNO-406 (refs } 56,77) \\
\text { Liver function abnormalities }{ }^{\mathrm{b}} \\
\text { Thrombocytopenia }^{\mathrm{b}} \\
\text { Elevated transaminase } \\
\text { Intrahepatic cholestasis } \\
\text { Renal failure secondary to tumor } \\
\text { lysis syndrome }\end{array}$ & \\
\hline $\begin{array}{l}\text { Ponatinib (AP24534) })^{(\text {ref552, 53) }} \text { Nausea } \\
\text { Fatigue } \\
\text { Vomiting } \\
\text { Headache } \\
\text { Arthralgia } \\
\text { Hot flush } \\
\text { Increased glucose } \\
\text { Increased lipase } \\
\text { Muscle spasms } \\
\text { Rash } \\
\text { Thrombocytopenia } \\
\text { Neutropenia } \\
\text { Dose-limiting toxicity } \\
\text { Elevated pancreatic enzymes } \\
\text { Pancreatitis } \\
\text { Rash }\end{array}$ & \\
\hline $\begin{array}{l}\text { Danusertib }(\text { PHA-739358) } \\
\text { Diarref. 57) } \\
\text { Pyrexia } \\
\text { Headache } \\
\text { Dyspnea } \\
\text { Nausea }\end{array}$ & \\
\hline $\begin{array}{l}\text { Omacetaxine (homoharringtonine) } \\
\text { Fatigue } \\
\text { Nausea } \\
\text { Vomiting } \\
\text { Dizziness } \\
\text { Weight loss } \\
\text { Thrombocytopenia } \\
\text { Anemia } \\
\text { Neutropenia }\end{array}$ & \\
\hline
\end{tabular}

Abbreviations: ALT, alanine aminotransferase; AST, aspartate aminotrans-

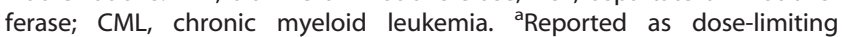
toxicities at a dose of $200 \mathrm{mg}$ twice daily with tablets. ${ }^{\mathrm{b}}$ Reported as dose-limiting toxicities at a dose of $480 \mathrm{mg}$ twice daily. be reinstituted at a lower dose. ${ }^{65,67}$ Patients with autoimmune disease, hypertension, cardiovascular disease, capillary leak syndrome or who are in myeloid BC may be more vulnerable to pleural effusions. More intensive monitoring of these patients should be considered. ${ }^{66}$ With respect to $\mathrm{PAH}$, the FDA issued a drug safety communication in October 2011 recommending that patients be evaluated for underlying cardiopulmonary conditions before and during dasatinib therapy. Patients who present with symptoms of PAH, such as dyspnea, fatigue and edema, should be evaluated for $\mathrm{PAH}$, and dasatinib should be permanently discontinued in patients confirmed to have $\mathrm{PAH} .{ }^{68}$

Rash, pruritus and headache are predominantly seen with nilotinib. As with most cases of rash related to TKI therapy, they tend to be mild or moderate and typically appear early in the treatment course. ${ }^{66}$ Topical or systemic steroid treatment is recommended; if the rash is severe, dose reduction, interruption or discontinuation is required. ${ }^{65}$ Supportive care is recommended to patients with headache, but it is seldom severe and is typically self-limiting. ${ }^{65}$ Musculoskeletal complaints, including muscle cramps and pain, are seen with all three approved BCR-ABL1 TKIs and can often be treated with calcium supplements and tonic water. Hyperglycemia has been observed with nilotinib use, and cases are usually mild, transient and manageable. Although evidence suggests that the presence of preexisting diabetes does not predispose patients to hyperglycemia during nilotinib treatment, $^{69}$ patients who are at risk of defects in glucose metabolism should be monitored closely.

\section{Hepatic toxicity}

AEs associated with hepatic toxicity are identified by liver function testing, and patients receiving TKI therapy should be queried regarding their use of other hepatotoxic agents. In patients receiving imatinib who experience a grade $2 \mathrm{AE}$, treatment should be interrupted until the $A E$ returns to grade $\leqslant 1$, and the dose reduced on resumption of therapy. If the $A E$ is grade $3 / 4$, however, a change to another TKI or enrollment in a clinical trial should be considered. With nilotinib, grade $\geqslant 3 \mathrm{AEs}$ of elevated lipase, amylase, bilirubin (indirect bilirubin) or hepatic transaminase should be managed with dose interruption until levels return to grade $\leqslant 1 .{ }^{65}$ No specific management recommendations regarding hepatic toxicity are made for dasatinib, but the general recommendation for any grade $2 / 3$ nonhematologic $A E$ not responsive to symptomatic measures is to treat it as grade 4 and interrupt treatment until the grade is 1 or lower. Treatment should be reinstated at a lower dose depending on the severity of the initial event. ${ }^{65}$

\section{Hematologic AEs}

Cytopenias are the most frequent all-grade and grade 3/4 AEs for TKIs, and are the primary cause of dose reductions or treatment interruptions. $^{66}$ The frequency of grade 3/4 AEs because of myelosuppression increases with the severity of the disease, ${ }^{66}$ although patients in AP or BC may have cytopenias related to disease. ${ }^{65}$ Grade 3/4 hematologic AEs are typically managed with dose interruptions followed by resumption of treatment at a reduced dose. For neutropenia and thrombocytopenia, myeloid growth factors can be used in combination with TKIs to offset myelosuppression. ${ }^{65,66}$ For grade 3/4 anemia, erythropoiesisstimulating agents, although effective, are not recommended by the Centers for Medicaid and Medicare Services or the FDA, ${ }^{65}$ based on evidence of increased risk of $A E s$ in patients with CML taking erythropoiesis-stimulating agents. ${ }^{70}$

\section{Potential effects on pregnancy and fertility}

Women of childbearing potential should be advised to avoid becoming pregnant while receiving TKI therapy. ${ }^{3,4,16}$ Furthermore, 
TKls must be immediately discontinued if a patient becomes pregnant on therapy. These agents are in pregnancy category $D$, indicating that they are associated with positive evidence of human fetal risk.

Animal studies suggest that TKI treatment can affect male and female reproductive systems. At levels of exposure in laboratory animals lower than that expected with standard dosing in humans, there were signs of deformation of the male and female reproductive organs with dasatinib and imatinib, but not nilotinib. ${ }^{4,16}$ At present, however, the effect of BCR-ABL1 TKI therapy on human male and female fertility is not known.

\section{Cardiotoxic effects}

Nilotinib and dasatinib should be avoided or used with caution in patients with hypokalemia, hypomagnesemia or long QT syndrome. Hypokalemia or hypomagnesemia must be corrected before administration, and drugs known to prolong the QT interval should be avoided. ${ }^{3,4}$ Specific to nilotinib, its use in combination with strong CYP3A4 inhibitors should be avoided, and it should be used with caution in patients with hepatic impairment. Electrocardiograms should be administered at baseline, 7 days after initiation, and periodically thereafter, as well as following any dose adjustments. ${ }^{4}$

Further research clearly is needed to better understand the mechanisms responsible for the cardiotoxic effects observed with TKIs. Such effects may be more evident in vulnerable populations; as seen with nilotinib, the incidence and severity of QTc prolongation appear to differ depending on the settings in which these agents are used, with fewer events in newly diagnosed patients than in previously treated patients. It should be noted that in the front-line setting, no significant cardiac toxicity, either congestive heart failure or QTc prolongation, was seen in the ENESTnd or the DASISION studies in either the study or standard arms.

\section{CONCLUSIONS}

Significant advances in the development of new CML therapies over the past decade have dramatically improved the outcomes for CML patients. The relationship of $\mathrm{AEs}$ to poor treatment adherence and of low adherence to suboptimal response supports the need for careful management of AEs. Although unmanageable $A E s$ indicate intolerance to therapy, many $A E s$ observed with front-line and second-line TKI treatment can be managed with supportive care. Proactive vigilance for potential AEs and treatment strategies to reduce symptom burden will help to minimize patient intolerance. To this end, development of newer agents will increase the armamentarium available to patients with difficult-to-manage symptoms or AEs.

Alertness to patients who may be experiencing intolerable AEs, even low-grade AEs, is imperative. At each clinic visit, practitioners should query patients about the presence of AEs, particularly persistent AEs, low-grade AEs and AEs that may cause patients to skip doses or decrease their dose. Patients may independently alter treatment in an attempt to mitigate the impact of AEs. ${ }^{8}$ Proactive assessment of AEs minimizes the chance of unreported AEs, which in turn may prevent poor adherence, and provides an opportunity to institute an early intervention strategy to manage the AE.

With the two recent phase 3 clinical trials findings indicating that nilotinib and dasatinib had superior efficacy compared with imatinib, clinical experience with these TKls in different settings is likely to increase. Indeed, the updated guidelines from the NCCN do not distinguish between imatinib, nilotinib or dasatinib in the choice of primary treatment in newly diagnosed patients with CML-CP. ${ }^{65}$ Comfort with identifying and managing AEs allows physicians to more optimally manage their patients with CML.
Fortunately, most AEs in the front-line setting can be readily managed, especially when they are addressed promptly.

\section{CONFLICT OF INTEREST}

Dr DeAngelo has served as a consultant for Novartis Pharmaceuticals, Bristol-Myers Squibb and Ariad Pharmaceuticals.

\section{ACKNOWLEDGEMENTS}

Financial support for medical editorial assistance was provided by Novartis Pharmaceuticals. I thank Mariana Ovnic and Anna Lau of Percolation Communications LLC for their medical editorial assistance.

\section{REFERENCES}

1 O'Brien SG, Guilhot F, Larson RA, Gathmann I, Baccarani M, Cervantes F et al. Imatinib compared with interferon and low-dose cytarabine for newly diagnosed chronic-phase chronic myeloid leukemia. N Engl J Med 2003; 348: 994-1004.

2 Deininger M, O'Brien SG, Guilhot F, Goldman JM, Hochhaus A, Hughes TP et al. International Randomized Study of Interferon versus STI571 (IRIS) 8-year follow up: sustained survival and low risk for progression or events in patients with newly diagnosed chronic myeloid leukemia in chronic phase (CML-CP) treated with imatinib. Blood (ASH Annual Meeting Abstracts) 2009; 114: abstract 1126.

3 Sprycel ${ }^{\mathbb{R}}$ (dasatinib) (prescribing information). Princeton, NJ: Bristol Myers-Squibb Company, 2011.

4 Tasigna $^{\mathbb{R}}$ (nilotinib) (prescribing information). East Hanover, NJ: Novartis Pharmaceuticals Corporation, 2012.

5 Saglio G, Kim DW, Issaragrisil S, le Coutre P, Etienne G, Lobo C et al. Nilotinib versus imatinib for newly diagnosed chronic myeloid leukemia. $N$ Engl J Med 2010; 362: 2251-2259.

6 Kantarjian H, Shah NP, Hochhaus A, Cortes J, Shah S, Ayala M et al. Dasatinib versus imatinib in newly diagnosed chronic-phase chronic myeloid leukemia. N Engl J Med 2010; 362: 2260-2270.

7 Marin D, Bazeos A, Mahon FX, Eliasson L, Milojkovic D, Bua M et al. Adherence is the critical factor for achieving molecular responses in patients with chronic myeloid leukemia who achieve complete cytogenetic responses on imatinib. J Clin Oncol 2010; 28: 2381-2388.

8 Williams LA, Ault P, Cleeland CS, Reynolds RJ, Shah NA, Shah PK et al. Symptom burden in chronic myeloid leukemia (CML). J Clin Oncol (Meeting Abstracts) 2010; 28: abstract 6133 .

9 Eliasson L, Clifford S, Barber N, Marin D. Exploring chronic myeloid leukemia patients' reasons for not adhering to the oral anticancer drug imatinib as prescribed. Leuk Res 2011; 35: 626-630.

10 Noens $L$, van Lierde MA, De Bock R, Verhoef $G$, Zachee $P$, Berneman $Z$ et al. Prevalence, determinants, and outcomes of nonadherence to imatinib therapy in patients with chronic myeloid leukemia: the ADAGIO study. Blood 2009; 113: 5401-5411.

11 Guilhot F, Coombs J, Zernovak O, Szczudlo T, Rosti G. A global retrospective and physician-based analysis of adherence to tyrosine kinase inhibitor (TKI) therapies for chronic myeloid leukemia (CML). Blood (ASH Annual Meeting Abstracts) 2010; 116: abstract 1514.

12 Ganesan P, Sagar TG, Dubashi B, Rajendranath R, Kannan K, Cyriac S et al. Nonadherence to imatinib adversely affects event free survival in chronic phase chronic myeloid leukemia. Am J Hematol 2011; 86: 471-474.

13 Ibrahim AR, Eliasson L, Apperley JF, Milojkovic D, Bua M, Szydlo R et al. Poor adherence is the main reason for loss of CCyR and imatinib failure for chronic myeloid leukemia patients on long-term therapy. Blood 2011; 117: 3733-3736.

14 Kantarjian $\mathrm{H}$, Pasquini $\mathrm{R}$, Hamerschlak N, Rousselot $\mathrm{P}$, Holowiecki J, Jootar $\mathrm{S}$ et al. Dasatinib or high-dose imatinib for chronic-phase chronic myeloid leukemia after failure of first-line imatinib: a randomized phase 2 trial. Blood 2007; 109: $5143-$ 5150.

15 Druker BJ, Guilhot F, O'Brien SG, Gathmann I, Kantarjian H, Gattermann N et al. Five-year follow-up of patients receiving imatinib for chronic myeloid leukemia. $N$ Engl J Med 2006; 355: 2408-2417.

16 Gleevec $^{\mathbb{R}} \quad$ (imatinib mesylate) (prescribing information). East Hanover, NJ: Novartis Pharmaceuticals Corporation, 2012.

17 Kerkelä R, Grazette L, Yacobi R, lliescu C, Patten R, Beahm C et al. Cardiotoxicity of the cancer therapeutic agent imatinib mesylate. Nat Med 2006; 12: 908-916.

18 Force T, Krause DS, Van Etten RA. Molecular mechanisms of cardiotoxicity of tyrosine kinase inhibition. Nat Rev Cancer 2007; 7: 332-344.

19 Guilhot F, Apperley J, Kim DW, Bullorsky EO, Baccarani M, Roboz GJ et al. Dasatinib induces significant hematologic and cytogenetic responses in patients with 
imatinib-resistant or -intolerant chronic myeloid leukemia in accelerated phase. Blood 2007; 109: 4143-4150.

20 Hochhaus A, Kantarjian HM, Baccarani M, Lipton JH, Apperley JF, Druker BJ et al. Dasatinib induces notable hematologic and cytogenetic responses in chronicphase chronic myeloid leukemia after failure of imatinib therapy. Blood 2007; 109: 2303-2309.

21 Kantarjian HM, Giles F, Gattermann N, Bhalla K, Alimena G, Palandri F et al. Nilotinib (formerly AMN107), a highly selective BCR-ABL tyrosine kinase inhibitor, is effective in patients with Philadelphia chromosome-positive chronic myelogenous leukemia in chronic phase following imatinib resistance and intolerance. Blood 2007; 110: 3540-3546.

22 le Coutre P, Ottmann OG, Giles F, Kim DW, Cortes J, Gattermann N et al. Nilotinib (formerly AMN107), a highly selective BCR-ABL tyrosine kinase inhibitor, is active in patients with imatinib-resistant or -intolerant accelerated-phase chronic myelogenous leukemia. Blood 2008; 111: 1834-1839.

23 Powell BL, Khoury HJ, Lipton JH, Rizzieri DA, Williams D, Turner AR. Nilotinib responses and tolerability confirmed in North American patients with chronic myeloid leukemia (CML) from ENACT (Expanding Nilotinib Access in Clinical Trials). Blood (ASH Annual Meeting Abstracts) 2009; 114: abstract 3295.

24 Fridericia LS. Die Systolendauer im Elektrokardiogramm bei normalen Menschen und bei Herzkranken. Acta Med Scand 1920; 53: 469-486.

25 Kantarjian HM, Giles FJ, Bhalla KN, Pinilla-lbarz J, Larson RA, Gattermann N et al. Nilotinib is effective in patients with chronic myeloid leukemia in chronic phase after imatinib resistance or intolerance: 24-month follow-up results. Blood 2011; 117: $1141-1145$.

26 Aichberger $\mathrm{KJ}$, Herndlhofer S, Schernthaner GH, Schillinger M, MitterbauerHohendanner $G$, Sillaber $C$ et al. Progressive peripheral arterial occlusive disease and other vascular events during nilotinib therapy in CML. Am J Hematol 2011; 86 533-539.

27 Giles FJ, Mauro MJ, Hong F, Ortmann C-E, Woodman RC, LeCoutre PD et al. Retrospective cohort analysis of peripheral arterial occlusive disease (PAOD) events in patients (pts) with chronic myeloid leukemia in chronic phase (CML-CP). Blood (ASH Annual Meeting Abstracts) 2011; 118: abstract 2757.

28 Hadzijusufovic E, Herndlhofer S, Aichberger KJ, Ghanim V, Suppan V, CernyReiterer $\mathrm{S}$ et al. Nilotinib exerts direct effects on vascular endothelial cells and may act as a co-trigger of atherosclerosis in patients with $\mathrm{Ph}+\mathrm{CML}$. Blood (ASH Annual Meeting Abstracts) 2011; 118: abstract 2753.

29 Le Coutre P, Rea D, Abruzzese E, Dombret H, Trawinska MM, Herndlhofer S et al. Severe peripheral arterial disease during nilotinib therapy. J Natl Cancer Inst 2011 103: $1347-1348$

30 Tefferi A, Letendre L. Nilotinib treatment-associated peripheral artery disease and sudden death: yet another reason to stick to imatinib as front-line therapy for chronic myelogenous leukemia. Am J Hematol 2011; 86: 610-611.

31 Cortes JE, Hochhaus A, le Coutre PD, Rosti G, Pinilla-lbarz J, Jabbour E et al. Minimal cross-intolerance with nilotinib in patients with chronic myeloid leukemia in chronic or accelerated phase who are intolerant to imatinib. Blood 2011 117: $5600-5606$.

32 Nicolini FE, Masszi T, Shen Z, Gallagher NJ, Jootar S, Powell BL et al. Expanding Nilotinib Access in Clinical Trials (ENACT), an open-label multicenter study of oral nilotinib in adult patients with imatinib-resistant or -intolerant chronic myeloid leukemia in accelerated phase or blast crisis. Leuk Lymphoma 2011; 53: 907-914.

33 Nicolini FE, Turkina A, Shen ZX, Gallagher N, Jootar S, Powell BL et al. Expanding Nilotinib Access in Clinical Trials (ENACT): An open-label, multicenter study of oral nilotinib in adult patients with imatinib-resistant or imatinib-intolerant philadelphia chromosome-positive chronic myeloid leukemia in the chronic phase. Cancer 2011; 118: 118-126.

34 Ottmann O, Dombret H, Martinelli G, Simonsson B, Guilhot F, Larson RA et al Dasatinib induces rapid hematologic and cytogenetic responses in adult patients with Philadelphia chromosome positive acute lymphoblastic leukemia with resistance or intolerance to imatinib: interim results of a phase 2 study. Blood 2007; 110: 2309-2315.

35 Cortes J, Rousselot P, Kim DW, Ritchie E, Hamerschlak N, Coutre S et al. Dasatinib induces complete hematologic and cytogenetic responses in patients with imatinib-resistant or -intolerant chronic myeloid leukemia in blast crisis. Blood 2007, 109: 3207-3213.

36 Quintas-Cardama A, Kantarjian H, O'Brien S, Borthakur G, Bruzzi J, Munden R et al. Pleural effusion in patients with chronic myelogenous leukemia treated with dasatinib after imatinib failure. J Clin Oncol 2007; 25: 3908-3914.

37 Guerin A, Wu EQ, Bollu VK, Williams D, Guo A, de Leon DP et al. The economic burden of pleural effusions in patients with chronic myeloid leukemia treated with tyrosine kinase inhibitors. J Med Econ 2012; e-pub ahead of print.

38 Dumitrescu D, Seck C, Ten Freyhaus H, Gerhardt F, Erdmann E, Rosenkranz S. Fully reversible pulmonary arterial hypertension associated with dasatinib treatment for chronic myeloid leukaemia. Eur Respir J 2011; 38: 218-220.
39 Hennigs JK, Keller G, Baumann HJ, Honecker F, Kluge S, Bokemeyer C et al. Multi tyrosine kinase inhibitor dasatinib as novel cause of severe pre-capillary pulmonary hypertension? BMC Pulm Med 2011; 11: 30.

40 Mattei D, Feola M, Orzan F, Mordini N, Rapezzi D, Gallamini A. Reversible dasatinib-induced pulmonary arterial hypertension and right ventricle failure in a previously allografted CML patient. Bone Marrow Transplant 2009; 43: 967-968.

41 Montani D, Bergot E, Gunther S, Savale L, Bergeron A, Bourdin A et al. Pulmonary arterial hypertension in patients treated by dasatinib. Circulation 2012; 125: 2128 2137

42 Orlandi EM, Rocca B, Pazzano AS, Ghio S. Reversible pulmonary arterial hypertension likely related to long-term, low-dose dasatinib treatment for chronic myeloid leukaemia. Leuk Res 2012; 36: e4-e6.

43 Rasheed W, Flaim B, Seymour JF. Reversible severe pulmonary hypertension secondary to dasatinib in a patient with chronic myeloid leukemia. Leuk Res 2009; 33: 861-864.

44 Mauro MJ, Baccarani M, Cervantes F, Lipton JH, Matloub Y, Sinha R et al. Dasatinib 2-year efficacy in patients with chronic-phase chronic myelogenous leukemia (CML-CP) with resistance or intolerance to imatinib (START-C). J Clin Oncol (Meeting Abstracts) 2008; 26: abstract 7009.

45 Khoury HJ, Goldberg SL, Mauro MJ, Stone RM, Matloub Y, Chen T et al. Dasatinib lack of cross intolerance to imatinib in patients (pts) with chronic myelogenous leukemia chronic phase (CML-CP) intolerant to imatinib: a retrospective analysis of safety. J Clin Oncol (Meeting Abstracts) 2008; 26: abstract 7015.

46 Kantarjian HM, Hochhaus A, Saglio G, De Souza Santos FP, Flinn IW, Stenke L et al. Nilotinib versus imatinib for the treatment of patients with newly diagnosed chronic phase, Philadelphia chromosome-positive, chronic myeloid leukaemia: 24-month minimum follow-up of the phase 3 randomised ENESTnd trial. Lancet Oncol 2011; 12: 841-851.

47 Radich JP, Kopecky KJ, Kamel-Reid S, Stock W, Paietta E, Wadleigh M et al. A randomized phase II trial of dasatinib $100 \mathrm{mg}$ vs imatinib $400 \mathrm{mg}$ in newly diagnosed chronic myeloid leukemia in chronic phase (CML-CP): the S0325 intergroup trial. Blood (ASH Annual Meeting Abstracts) 2010; 116: abstract LBA-6.

48 Kantarjian HM, Shah NP, Cortes JE, Baccarani M, Agarwal MB, Undurraga MS et al. Dasatinib or imatinib in newly diagnosed chronic phase chronic myeloid leukemia: 2-year follow-up from a randomized phase 3 trial (DASISION). Blood 2012; 119: $1123-1129$.

49 Saglio G, LeCoutre PD, Pasquini R, Jootar S, Nakamae H, Flinn IW et al. Nilotinib versus imatinib in patients (pts) with newly diagnosed Philadelphia chromosomepositive $(\mathrm{Ph}+)$ chronic myeloid leukemia in chronic phase (CML-CP): ENESTnd 36-month (mo) follow-up. Blood (ASH Annual Meeting Abstracts) 2011; 118: abstract 452.

50 Cortes JE, Kantarjian HM, Brummendorf TH, Kim DW, Turkina AG, Shen ZX et al. Safety and efficacy of bosutinib (SKI-606) in chronic phase Philadelphia chromosome-positive CML patients with resistance or intolerance to imatinib. Blood 2011; 118: 4567-4576.

51 Khoury HJ, Cortes JE, Kantarjian HM, Gambacorti-Passerini C, Baccarani M, Kim DW et al. Bosutinib is active in chronic phase chronic myeloid leukemia after imatinib and dasatinib and/or nilotinib therapy failure. Blood 2012; 119: 3403-3412.

52 Cortes J, Talpaz M, Bixby D, Deininger M, Shah N, Flinn IW et al. A phase 1 trial of oral ponatinib (AP24534) in patients with refractory chronic myelogenous leukemia $(C M L)$ and other hematologic malignancies: emerging safety and clinical response findings. Blood (ASH Annual Meeting Abstracts) 2010; 116: abstract 210.

53 Talpaz M, Cortes JE, Deininger MW, Shah NP, Flinn IW, Mauro MJ et al. Phase I trial of AP24534 in patients with refractory chronic myeloid leukemia (CML) and hematologic malignancies. J Clin Oncol (Meeting Abstracts) 2010; 28: abstract 6511.

54 Eide CA, Adrian LT, Tyner JW, Mac Partlin M, Anderson DJ, Wise SC et al. The ABL switch control inhibitor DCC-2036 is active against the chronic myeloid leukemia mutant BCR-ABLT315I and exhibits a narrow resistance profile. Cancer Res 2011 71: $3189-3195$.

55 Cortes JE, Talpaz M, Kantarjian HM, Smith H, Bixby D, Rafferty U et al. A phase 1 study of DCC-2036, a novel oral inhibitor of BCR-ABL kinase, in patients with Philadelphia chromosome positive $(\mathrm{Ph}+$ ) leukemias including patients with T315I mutation. Blood (ASH Annual Meeting Abstracts) 2011; 118: abstract 601.

56 Kantarjian H, le Coutre P, Cortes J, Pinilla-lbarz J, Nagler A, Hochhaus A et al. Phase 1 study of INNO-406, a dual Abl/Lyn kinase inhibitor, in Philadelphia chromosome-positive leukemias after imatinib resistance or intolerance. Cancer 2010 116: 2665-2672.

57 Cortes-Franco J, Dombret $\mathrm{H}$, Schafhausen P, Brummendorf TH, Boissel N, Latini F et al. Danusertib hydrochloride (PHA-739358), a multi-kinase aurora inhibitor elicits clinical benefit in advanced chronic myeloid leukemia and Philadelphia chromosome positive acute lymphoblastic leukemia. Blood (ASH Annual Meeting Abstracts) 2009; 114: abstract 864 .

58 Ayoubi M, Kantarjian HM, Wierda W, Ferrajoli A, Hiteshew J, Estrov Z et al. A phase 2 study of the combination of omacetaxine and imatinib in the treatment of 
patients with chronic myeloid leukemia $(\mathrm{CML})$ in advanced stages or after failure to imatinib. Blood (ASH Annual Meeting Abstracts) 2009; 114: abstract 2193.

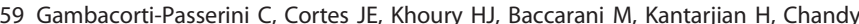
$M$ et al. Safety and efficacy of bosutinib in patients with AP and BP CML and ph + ALL following resistance/intolerance to imatinib and other TKIs: Update from study SKI-200. J Clin Oncol (Meeting Abstracts) 2010; 28: abstract 6509.

60 Cortes JE, Maru A, Souza CAAD, Guilhot F, Duvillie L, Powell C et al. Bosutinib versus imatinib in newly diagnosed chronic phase chronic myeloid leukemia BELA trial: 24-month follow-up. Blood (ASH Annual Meeting Abstracts) 2011; 118: abstract 455 .

61 Kantarjian HM, Cortes JE, Kim D-W, Khoury HJ, Brummendorf TH, Porkka K et al. Bosutinib safety profile and management of toxicities in leukemia patients with resistance or intolerance to imatinib and other tyrosine kinase inhibitors. Blood (ASH Annual Meeting Abstracts) 2011; 118: abstract 2760.

62 Gambacorti-Passerini C, Cortes JE, Harris P, Powell C, Countouriotis A, Kantarjian HM. Safety and management of toxicities in the BELA trial of bosutinib versus imatinib in newly diagnosed chronic phase chronic myeloid leukemia. Blood (ASH Annual Meeting Abstracts) 2011; 118: abstract 1685.

63 Cortes JE, Kantarjian HM, Shah N, Bixby D, Mauro MJ, Flinn IW et al. Subset analysis of response to treatment of chronic phase CML in a phase 1 study of ponatinib in refractory hematologic malignancies. Blood (ASH Annual Meeting Abstracts) 2011; 118: abstract 602.

64 Cortes JE, Kim D-W, Pinilla-lbarz J, Le Coutre PD, Chuah C, Nicolini FE et al. Initial findings from the PACE trial: a pivotal phase 2 study of ponatinib in patients with $\mathrm{CML}$ and $\mathrm{Ph}+\mathrm{ALL}$ resistant or intolerant to dasatinib or nilotinib, or with the T315I mutation. Blood (ASH Annual Meeting Abstracts) 2011; 118: abstract 109.

65 National Comprehensive Cancer Network. NCCN Clinical Practice Guidelines in Oncology. Chronic myelogenous leukemia. Version 2.2012. http://www.nccn.org/ professionals/physician_gls/PDF/cml.pdf. Accessed 24 May 2012

66 Mauro MJ, Deininger MW. Management of drug toxicities in chronic myeloid leukaemia. Best Pract Res Clin Haematol 2009; 22: 409-429.

67 Masiello D, Gorospe 3rd G , Yang AS. The occurrence and management of fluid retention associated with TKI therapy in $\mathrm{CML}$, with a focus on dasatinib. $J$ Hematol Oncol 2009; 2: 46

68 US Food and Drug Administration. FDA Drug Safety Communication: Sprycel (dasatinib) and risk of pulmonary arterial hypertension.. http://www.fda.gov/ Drugs/DrugSafety/ucm275155.htm. Accessed 8 May 2012.

69 Saglio G, Larson RA, Hughes TP, Issaragrisil S, Turkina AG, Marin D et al. Efficacy and safety of nilotinib in chronic phase $(\mathrm{CP})$ chronic myeloid leukemia $(\mathrm{CML})$ patients (Pts) with type 2 diabetes in the ENESTnd trial. Blood (ASH Annual Meeting Abstracts) 2010; 116: abstract 3430.

70 Centers for Medicare \& Medicaid Services. Decision Memo for Erythropoiesis Stimulating Agents (ESAs) for Non-renal Disease Indications (CAG-00383N). Baltimore, MD: CMS, 2007.

71 Cortes J, Kantarjian HM, Baccarani M, Brummendorf TH, Liu D, Ossenkoppele G et al. A phase 1/2 study of SKI-606, a dual inhibitor of Src and Abl kinases, in adult patients with Philadelphia chromosome positive $(\mathrm{Ph}+)$ chronic myelogenous leukemia $(C M L)$ or acute lymphocytic leukemia ( $A L L)$ relapsed, refractory or intolerant of imatinib. Blood (ASH Annual Meeting Abstracts) 2006; 108: abstract 168.

72 Cortes J, Kantarjian HM, Kim D-W, Khoury HJ, Turkina AG, Shen Z-X et al. Efficacy and safety of bosutinib (SKI-606) in patients with chronic phase (CP) Ph + chronic myelogenous leukemia (CML) with resistance or intolerance to imatinib. Blood (ASH Annual Meeting Abstracts) 2008; 112: abstract 1098.

73 Gambacorti-Passerini C, Kim D-W, Kantarjian HM, Brummendorf TH, Dyagil I, Griskevicius $\mathrm{L}$ et al. An ongoing phase 3 study of bosutinib (SKI-606) versus imatinib in patients with newly diagnosed chronic phase chronic myeloid leukemia. Blood (ASH Annual Meeting Abstracts) 2010; 116: abstract 208.

74 Cortes J, Bruemmendorf T, Kantarjian H, Khoury J, Rosti G, Fischer T et al. Efficacy and safety of bosutinib (SKI-606) among patients with chronic phase $\mathrm{Ph}+$ chronic myelogenous leukemia (CML). Blood (ASH Annual Meeting Abstracts) 2007; 110: abstract 733 .

75 Cortes JE, Kantarjian H, Brummendorf T, Khoury HJ, Kim D, Turkina A et al. Safety and efficacy of bosutinib (SKI-606) in patients (pts) with chronic phase (CP) chronic myeloid leukemia (CML) following resistance or intolerance to imatinib (IM). J Clin Oncol (Meeting Abstracts) 2010; 28: abstract 6502.

76 Gambacorti-Passerini C, Kantarjian H, Bruemmendorf T, Martinelli G, Baccarani M, Fischer T et al. Bosutinib (SKI-606) demonstrates clinical activity and is well tolerated among patients with $\mathrm{AP}$ and $\mathrm{BP} \mathrm{CML}$ and $\mathrm{Ph}+\mathrm{ALL}$. Blood (ASH Annual Meeting Abstracts) 2007; 110: abstract 473.

77 Kantarjian HM, Cortes J, le Coutre P, Nagler A, Pinilla J, Hochhaus A et al. A phase I study of INNO-406 in patients with advanced Philadelphia $(\mathrm{Ph}+)$ chromosomepositive leukemias who are resistant or intolerant to imatinib and second generation tyrosine kinase inhibitors. Blood (ASH Annual Meeting Abstracts) 2007; 110: abstract 469.

This work is licensed under the Creative Commons AttributionNonCommercial-No Derivative Works 3.0 Unported License. To view a copy of this license, visit http://creativecommons.org/licenses/by-nc-nd/3.0/ 